\title{
Direct Oral Anticoagulants for the Treatment of Venous Thromboembolism in Japan
}

\author{
Mashio Nakamura, Norikazu Yamada and Masaaki Ito
}

Department of Cardiology and Nephrology, Mie University Graduate School of Medicine, Tsu, Japan

Direct oral anticoagulants (DOACs) were developed to compensate for the demerits of warfarin. In Japan, three factor $\mathrm{Xa}$ inhibitors are used for the treatment of venous thromboembolism (VTE): edoxaban, rivaroxaban, and apixaban. Despite problems, such as the inability to monitor their effect and the lack of an antidote, these inhibitors have the same efficacy as conventional treatment with warfarin, and they are associated with a significantly high degree of safety in relation to hemorrhagic complications. East Asians, including Japanese, suffer from hemorrhage more frequently; therefore, DOACs are considered to be highly effective. Although there is no evidence to date, DOACs may be effective in a wide variety of ways, including the possibility that they prevent recurrence over the long term, reduce the length of hospitalization, allow treatment to be started on an outpatient basis, and be effective in cancer patients.

Key words: Apixaban, Direct oral anticoagulant, Edoxaban, Rivaroxaban

\section{Introduction}

The main conventional anticoagulant treatments have included parenteral drugs, such as unfractionated heparin (UFH) and low-molecular-weight heparin (LMWH). Because of their molecular chemical characteristics, heparins are not absorbed easily in the gastrointestinal tract; however, parenteral drugs are very poorly suited for long-term anticoagulant therapy. In contrast, since its commercialization in the 1960 s, the vitamin $\mathrm{K}$ antagonist warfarin has contributed to clinical medicine through its use as the only oral anticoagulant. However, warfarin is limited in many ways, and its use entails a large burden. Specifically, warfarin has delayed drug efficacy, requires careful monitoring and frequent dose adjustments, requires different doses for each individual according to CYP2C9 activity, has a narrow safety range, is interactive with food-derived vitamin $\mathrm{K}$ and a large number of drugs, and requires

Address for correspondence: Mashio Nakamura, Department of Cardiology and Nephrology, Mie University Graduate School of Medicine, 2-174, Edobashi, Tsu 514-8507, Japan

E-mail: mashio@clin.medic.mie-u.ac.jp

Received: March 6, 217

Accepted for publication: March 8, 2017 patient education.

In recent years, activated factor X (factor Xa), which is an important serine protease in the coagulation cascade, and nonpeptide low molecular weight compounds that interfere with thrombin have been developed as oral anticoagulants designed to replace warfarin. These drugs do not require monitoring, and there is hope that they can be used as new anticoagulants that overcome the aforementioned problems with warfarin. Their clinical targets are the prevention of thromboembolism in atrial fibrillation, primary prevention of venous thromboembolism (VTE) in orthopedic surgery, and treatment of VTE. In Japan, dabigatran, rivaroxaban, apixaban, and edoxaban are used to prevent thromboembolism in atrial fibrillation; only edoxaban is used in the primary prevention of VTE in orthopedic surgery, and edoxaban, rivaroxaban, and apixaban are used in the treatment of VTE (Table 1) ${ }^{1-4)}$.

Here, we provide an outline of these new oral anticoagulants; that is, the direct oral anticoagulants (DOACs), and in particular their efficacy in the treatment of VTE and future prospects for their use. 
Table 1. Large clinical trials of direct oral anticoagulant for venous thromboembolism

\begin{tabular}{|c|c|c|c|c|}
\hline & Hokusai-VTE & EINSTEIN-DVT & EINSTEIN-PE & AMPLIFY \\
\hline Trial Method & Double blind & \multicolumn{2}{|c|}{ Open-label } & Double blind \\
\hline Regimen & $60 \mathrm{mg}(30 \mathrm{mg})$ once daily & \multicolumn{2}{|c|}{$\begin{array}{l}15 \mathrm{mg} \text { twice daily for } 3 \text { weeks followed } \\
\text { by } 20 \mathrm{mg} \text { once daily }\end{array}$} & $\begin{array}{l}10 \mathrm{mg} \text { twice daily } \\
\text { for a weeks followed } \\
\text { by } 5 \mathrm{mg} \text { twice daily }\end{array}$ \\
\hline Treatment Period & 3-12 months & \multicolumn{2}{|c|}{ 3, 6, 12 months } & 6 months \\
\hline Japanese Patients & 209 patients & N/A & $\mathrm{N} / \mathrm{A}$ & N/A \\
\hline Primary Efficacy Outcome & $\begin{array}{l}\text { Non-inferiority } \\
\text { (VTE recurrence) }\end{array}$ & $\begin{array}{l}\text { Non-inferiority } \\
\text { (VTE recurrence) }\end{array}$ & $\begin{array}{l}\text { Non-inferiority } \\
\text { (VTE recurrence) }\end{array}$ & $\begin{array}{l}\text { Non-inferiority } \\
\text { (VTE recurrence or } \\
\text { VTE related death) }\end{array}$ \\
\hline Primary Safety Outcome & $\begin{array}{c}\text { Superiority } \\
\text { (Major bleeding + CRNM) }\end{array}$ & $\begin{array}{l}\text { Non-inferiority } \\
\text { (Major bleeding + } \\
\text { CRNM) }\end{array}$ & $\begin{array}{l}\text { Non-inferiority } \\
\text { (Major bleeding + } \\
\text { CRNM) }\end{array}$ & $\begin{array}{c}\text { Superiority } \\
\text { (Major bleeding)) }\end{array}$ \\
\hline
\end{tabular}

CRNM, clinically relevant no major bleeding; N/A, not available; TTR, Target Therapeutic Range; VTE, venous thromboembolism From ref. 1-4.

\section{Pharmacological Characteristics of DOACs}

The new anticoagulants that overcome the problems associated with conventional drugs boast assured efficacy with little individual variation in only a single dose and they do not require monitoring. In addition, they are extremely safe, have a wide therapeutic range, are less hemorrhagic, and have rapid onset action. In Japan, all of the DOACs used for VTE therapy are factor $\mathrm{Xa}$ inhibitors (Fig. 1). Factor $\mathrm{Xa}$ is further upstream in the coagulation cascade compared to thrombin, and one molecule of factor Xa produces 1000 molecules of thrombin. Therefore, rather than inhibiting the enzymatic activity of thrombin, it is thought that inhibiting this production would be a more efficient way to suppress the coagulation response. In addition, although thrombin has a negative feedback action on blood coagulation systems other than blood coagulation activation, because factor $\mathrm{Xa}$ is selective to the blood coagulation system, it is more appropriate for use as a drug discovery target molecule.

In the search for drugs that could be used as anticoagulants that do not have the same problems as warfarin, compounds with high oral absorbability were discovered and investigated. However, because most are strongly basic in nature, they have insufficient oral absorbability. Before oral factor Xa, indirect factor Xa inhibitor, fondaparinux, which is injectable and dependent upon antithrombin, was available for use in the treatment and prevention of VTE. Then, in recent years, compounds that maintain $\mathrm{Xa}$ activity due to their reduced alkalinity and that have excellent oral absorbability were discovered and developed into multiple direct factor Xa inhibitors.

Table 2 shows the pharmacokinetic characteristics of edoxaban, rivaroxaban, and apixaban ${ }^{5,6}$. Rivaroxaban and edoxaban are administered once a day, and apixaban is administered twice a day. Each drug reaches maximum blood concentration within $4 \mathrm{~h}$ after administration, and their short half-life of approximately half a day means that they act 
<smiles>CN1CCc2nc(C(=O)N[C@H]3C[C@H](C(=O)N(C)C)CC[C@H]3NC(=O)C(=O)Nc3ccc(Cl)cn3)sc2C1</smiles><smiles>O=C(NCC1CN(c2ccc(N3CCOCC3=O)cc2)C(=O)O1)c1ccc(Cl)s1</smiles><smiles>COc1ccc(-n2nc(C(N)=O)c3c2C(=O)N(c2ccc(N4CCCCC4=O)cc2)CC3)cc1</smiles>

\section{Edoxaban}

Rivaroxaban

\section{Apixaban}

Fig. 1. Structures of the oral factor $\mathrm{Xa}$ inhibitors edoxaban, rivaroxaban, and apixaban

Table 2. Pharmacokinetic features of direct oral anticoagulants ${ }^{5,6)}$

\begin{tabular}{lccc}
\hline & Edoxaban & Rivaroxaban & Apixaban \\
\hline Target & Factor Xa & Factor Xa & Factor Xa \\
Molecular Weight (Da) & 548 & 436 & 460 \\
Clinical Development in Japan & DAIICHI SANKYO CO., Ltd. & Bayer Yakuhin, Ltd. & BMS K.K/ Pfizer Japan Inc. \\
Dosing & Once daily & Once daily & Twice daily \\
Time of maximum concentration (h) & $1-2$ & $2-4$ & $1-3$ \\
CYP metabolism (\%) & $<4$ & -66 & 25 \\
Bioavailability (\%) & 62 & 80 & 66 \\
Interaction with P-Glycoprotein-inhibitors & Yes & Yes & Yes \\
Protein binding (\%) & $40-59$ & $90-$ & $8-13$ \\
Half-life (h) & $9-11$ & 66 & $8-15$ \\
Renal excretion (\%) & $35-39$ & 25 \\
\hline
\end{tabular}

extremely quickly and exhibit anticoagulant effects from the day of administration. Most are metabolized in the liver by cytochrome P450, which means that the renal excretion rate of unaltered substances is relatively low.

\section{Clinical Effectiveness of DOACs When Used in VTE Therapy}

Edoxaban was shown to be effective and safe in the international clinical Hokusai-VTE trial, which included Japanese patients ${ }^{1)}$. A subanalysis of the East Asian population, including Japanese, also found that they are effective ${ }^{7)}$. Rivaroxaban was effective and safe in the international clinical EINSTEIN Pulmonary Embolism (PE)/Deep Vein Thrombosis (DVT) Trial ${ }^{2,3)}$, and apixaban was effective and safe in the international clinical AMPLIFY Trial ${ }^{4)}$. They were found to be safe for Japanese patients in the J-EINSTEIN Trial $^{8)}$ and the AMPLIFY-J Trial ${ }^{9)}$.

The Hokusai-VTE Trial began treating subjects with edoxaban after administering parenteral antico- 
agulants for at least 5 days to early-phase patients and then assessed the effectiveness and safety. The EINSTEIN PE/DVT Trial conducted treatment in the initial phase after onset of VTE using only oral drugs by administering rivaroxaban during the initial 3 weeks at 1.5 -fold the usual dose. The J-EINSTEIN Trial of Japanese subjects administered rivaroxaban 3 weeks after onset at a reduced dose that was three-quarters that used in the EINSTEIN PE/DVT Trial. The AMPLIFY Trial conducted treatment in the initial phase after onset of VTE using only oral drugs by administering apixaban during the initial week at 2-fold the usual dose.

Comparisons in all these trials of DOACs and warfarin indicated that the effectiveness (that is, the recurrence rate of symptomatic VTE) was not inferior and that safety (that is, the onset rate of hemorrhagic complications) of DOACs was superior. A subanalysis of the Hokusai-VTE Trial on PE at NT-proBNP $\geq$ $500 \mathrm{pg} / \mathrm{mL}$ indicated that edoxaban showed significantly more reduction in the onset of symptomatic VTE than warfarin (but less than heparin) ${ }^{10)}$. When East Asians, including Japanese, were compared to non-East Asians, DOACs showed equal incidences for hemorrhagic complications, while warfarin had markedly higher incidence. This suggests that DOACs have a great deal of merit for East Asians ${ }^{9}$.

\section{Problems with VTE Therapy Using DOACs}

Efficacy monitoring was impossible for all DOACs. Therefore, administration to patients whose DOACs blood levels may rise, such as the elderly, underweight patients, and patients with renal dysfunction, requires that sufficient attention be paid to the risk of hemorrhage. In addition, it must be kept in mind that there is no antidote at present; therefore, when interventional procedures are being considered, the use of UFH and other drugs with shorter half-lives should be considered. Currently, antidotes for Xa inhibitors are being developed, and we look forward to their early clinical application ${ }^{11)}$. There are also reports indicating that VTE often has complications in patients who are at risk of arteriosclerosis ${ }^{12,13)}$. In such cases, the combined use of antiplatelet drugs and DOACs is likely to be frequent. Because the combined use of antiplatelet drugs and DOACs increases the frequency of hemorrhage, the benefits and risks must be considered; thus, lower doses of DOACs should be considered.

Although three DOACs can now be used in VTE therapy, there are major differences in the initial administration regimens for each of them. Because there is currently no evidence regarding this topic, it is very difficult to determine which DOAC should be used for which type of VTE (Fig. 2). In addition, although dose reduction criteria for edoxaban have been established and its effectiveness has been verified in Phase III trials, there are no dose reduction criteria for rivaroxaban or apixaban. There is a strong sense that dose reduction criteria for Japanese, a population with many underweight and elderly members, are required, but there is no evidence regarding this issue at present. Thus, many issues regarding DOACs have not been elucidated in large-scale clinical trials, and there are many issues in which Japanese and patients of European descent differ. It is necessary to conduct further clinical trials designed to provide answers to these unanswered questions.

\section{New Developments in VTE Therapy in the Age of DOACs}

The possibility of recurrence during the chronic phase of VTE means that it is necessary to consider the long-term use of anticoagulants, particularly in cases of unprovoked VTE, in which this possibility remains at a constant rate for as long as 3 months after onset $^{14)}$. DOACs are safe anticoagulants that have a lower risk of hemorrhage than warfarin; as a result, they can be used for longer periods of time in VTE therapy. To further reduce the risk of hemorrhage with long-term use, the possibility of reducing the DOAC dose should be examined. The AMPLIFY-EXT Trial ${ }^{15)}$ indicated that apixaban administered continuously at a reduced dose of $2.5 \mathrm{mg}$ per dose twice a day after 6 months after VTE onset was effective.

Because DOACs are effective immediately after administration, they do not have the same onset delay as seen in warfarin, which leads to reduced hospitalization during the acute phase of VVTE. Patients whose conditions are stable and in whom the risk of VTE recurrence and hemorrhage is low may be discharged early and shifted to outpatient care. In addition, there seem to be no major problems with the use of DOAC therapy at VTE onset in moderate or mild cases of DVT. However, it is necessary to emphasize the reliability of treatment in cases of symptomatic $\mathrm{PE}$; therefore, further studies are required to determine whether oral drug therapy alone at onset is sufficient for these cases.

Cancer patients commonly experience VTE as a complication ${ }^{14)}$. The prognostic improvement effect of LMWH in cases of VTE complicating cancer has been elucidated ${ }^{16)}$, and LMWH is recommended for cancer patients with VTE in Europe and the United States. However, LMWH cannot be used as a VTE therapy in Japan, which means that only warfarin can 


\section{Injection Usual dose of DOAC}

\section{3-week, double-dose DOAC \\ Usual dose of DOAC}

\section{1-week, double-dose DOAC \\ Usual dose of DOAC}

\section{Usual dose of DOAC}

\section{Reduced dose of DOAC}

\section{Onset of VTE}

Fig. 2. Options for the regimen of direct oral anticoagulants for the initial treatment of venous thromboembolism in Japan

Patients at a greater risk of thrombosis are more prone to choosing the dosing regimens in the upper regimen, while patients at a greater risk of bleeding are more prone to choosing the dosing regimens in the lower regimen.

Table 3. Clinical questions in therapeutic application for the treatment of VTE with DOAC

What is the duration of administration of DOAC for VTE patients?

What patients can receive outpatient DOAC?

How is the safety of DOAC ensured in fragile patients?

Does DOAC have the utility for cancer patients?

What is the regimen of DOAC for isolated calf DVT?

DOAC, direct oral anticoagulant, VTE, venous thromboembolism

be used for long-term therapy. However, it is often difficult to adjust the dose of warfarin when used in combination with chemotherapy and because of fluctuations in platelet count. DOACs can be administered more safely to cancer patients than warfarin, and currently, their clinical effectiveness is being investigated worldwide ${ }^{17)}$.

\section{Conclusion}

When used as VTE therapy, DOACs are highly effective and have a great deal of potential. However, because there is little evidence regarding a variety of clinical questions (Table 3), further clinical trials and clinical data are required for the development of DOACs into safer drugs that are easier to use.

\section{Acknowledgment}

A part of this work was supported by JSPS KAKENHI Grant Number JP26461067.

\section{COI}

Mashio Nakamura has received remuneration from DAIICHI SANKYO COMPANY, LIMITED, Bayer Yakuhin, Ltd., Pfizer Japan Inc. and BristolMyers Squibb K.K.. Norikazu Yamada has received honoraria from Bayer Yakuhin, Ltd. and Bristol-Myers Squibb K.K.. Masaaki Ito has received Scholarship from Bayer Yakuhin, Ltd., Pfizer Japan Inc., Bristol-Myers Squibb K.K., DAIICHI SANKYO COMPANY, LIMITED and Nippon Boehringer Ingelheim Co.,Ltd.. 


\section{References}

1) Hokusai-VTE Investigators, Büller $H R$, Décousus $H$, Grosso MA, Mercuri M, Middeldorp S, Prins MH, Raskob GE, Schellong SM, Schwocho L, Segers A, Shi M, Verhamme P, Wells P: Edoxaban versus warfarin for the treatment of symptomatic venous thromboembolism. N Engl J Med, 2013; 369: 1406-1415

2) EINSTEIN Investigators, Bauersachs R, Berkowitz SD, Brenner B, Buller HR, Decousus H, Gallus AS, Lensing AW, Misselwitz F, Prins MH, Raskob GE, Segers A, Verhamme P, Wells P, Agnelli G, Bounameaux H, Cohen A, Davidson BL, Piovella F, Schellong S: Oral rivaroxaban for symptomatic venous thromboembolism. N Engl J Med, 2010; 363: 2499-2510

3) EINSTEIN-PE Investigators, Büller HR, Prins $\mathrm{MH}$, Lensin AW, Decousus H, Jacobson BF, Minar E, Chlumsky J, Verhamme P, Wells P, Agnelli G, Cohen A, Berkowitz SD, Bounameaux H, Davidson BL, Misselwitz F, Gallus AS, Raskob GE, Schellong S, Segers A: Oral rivaroxaban for the treatment of symptomatic pulmonary embolism. N Engl J Med, 2012; 366: 1287-1297

4) Agnelli G, Buller HR, Cohen A, Curto M, Gallus AS, Johnson M, Masiukiewicz U, Pak R, Thompson J, Raskob GE, Weitz JI; AMPLIFY Investigators: Oral apixaban for the treatment of acute venous thromboembolism. N Engl J Med, 2013; 369: 799-808

5) Ogawa S, Koretsune Y, Yasaka M, Aizawa Y, Atarashi H, Inoue $\mathrm{H}$, Kamakura S, Kumagai K, Mitamura H, Okumura K, Sugi K, Yamashita T: Antithrombotic therapy in atrial fibrillation: evaluation and positioning of new oral anticoagulant agents. Circ J, 2011; 75: 1539-1547

6) De Caterina R, Husted S, Wallentin L, Andreotti F, Arnesen $\mathrm{H}$, Bachmann F, Baigent C, Huber K, Jespersen J, Kristensen SD, Lip GY, Morais J, Rasmussen LH, Siegbahn A, Verheugt FW, Weitz JI; Coordinating Committee: New oral anticoagulants in atrial fibrillation and acute coronary syndromes: ESC Working Group on Thrombosis-Task Force on Anticoagulants in Heart Disease position paper. J Am Coll Cardiol, 2012; 59: 1413-1425

7) Nakamura M, Wang YQ, Wang C, Oh D, Yin WH, Kimura T, Miyazaki K, Abe K, Mercuri M, Lee LH, Segers A, Büller H: Efficacy and safety of edoxaban for treatment of venous thromboembolism: a subanalysis of East Asian patients in the Hokusai-VTE trial. J Thromb Haemost, 2015; 13: 1606-1614

8) Yamada N, Hirayama A, Maeda H, Sakagami S, Shikata $\mathrm{H}$, Prins $\mathrm{MH}$, Lensing AW, Kato M, Onuma J, Miyamoto Y, Iekushi K, Kajikawa M: Oral rivaroxaban for Japanese patients with symptomatic venous thromboembolism - the J-EINSTEIN DVT and PE program. Thromb J, 2015; 13: 2

9) Nakamura M, Nishikawa M, Komuro I, Kitajima I, Uet- suka Y, Yamagami T, Minamiguchi H, Yoshimatsu R, Tanabe K, Matsuoka N, Kanmuri K, Ogawa H: Apixaban for the Treatment of Japanese Subjects with Acute Venous Thromboembolism (AMPLIFY-J Study). Circ J, 2015; 79: 1230-1236

10) Brekelmans MP, Ageno W, Beenen LF, Brenner B, Buller HR, Chen CZ, Cohen AT, Grosso MA, Meyer G, Raskob G, Segers A, Vanassche T, Verhamme P, Wells PS, Zhang G, Weitz J: Recurrent venous thromboembolism in patients with pulmonary embolism and right ventricular dysfunction: a post-hoc analysis of the Hokusai-VTE study. Lancet Haematol, 2016; 3: e437-e445

11) Connolly SJ, Milling Jr. TJ, Eikelboom JW, Gibson CM, Curnutte JT, Gold A, Bronson MD, Lu G, Conley PB, Verhamme P, Schmidt J, Middeldorp S, Cohen AT, BeyerWestendorf J, Albaladejo P, Lopez-Sendon J, Goodman S, Leeds J, Wiens BL, Siegal DM, Zotova E, Meeks B, Nakamya J, Lim WT, Crowther M; ANNEXA-4 Investigators: Andexanet Alfa for Acute Major Bleeding Associated with Factor Xa Inhibitors. N Engl J Med, 2016; 375: 1131-1141

12) Hatakeyama K: CETP Activity: A Link between Lipid Metabolism and Coagulation System. J Atheroscler Thromb, 2016; 23: 1144-1146

13) Deguchi H, Banerjee Y, Elias DJ, Griffin JH: Elevated CETP Lipid Transfer Activity is Associated with the Risk of Venous Thromboembolism. J Atheroscler Thromb, 2016; 23: 1159-1167

14) Nakamura M, Miyata T, Ozeki Y, Takayama M, Komori K, Yamada N, Origasa H, Satokawa H, Maeda H, Tanabe N, Unno N, Shibuya T, Tanemoto K, Kondo K, Kojima $\mathrm{T}$ : Current venous thromboembolism management and outcomes in Japan. Circ J, 2014; 78: 708-717

15) Agnelli G, Buller HR, Cohen A, Curto M, Gallus AS, Johnson M, Porcari A, Raskob GE, Weitz JI; PLIFY-EXT Investigators: Apixaban for extended treatment of venous thromboembolism. N Engl J Med, 2013; 368: 699-708

16) Lee AY, Rickles FR, Julian JA, Gent M, Baker RI, Bowden C, Kakkar AK, Prins M, Levine MN: Randomized comparison of low molecular weight heparin and coumarin derivatives on the survival of patients with cancer and venous thromboembolism. J Clin Oncol, 2005; 23: 21232129

17) van Es N, Di Nisio M, Bleker SM, Segers A, Mercuri MF, Schwocho L, Kakkar A, Weitz JI, Beyer-Westendorf J, Boda Z, Carrier M, Chlumsky J, Décousus H, Garcia D, Gibbs H, Kamphuisen PW, Monreal M, Ockelford P, Pabinger I, Verhamme P, Grosso MA, Büller HR, Raskob GE: Edoxaban for treatment of venous thromboembolism in patients with cancer. Rationale and design of the Hokusai VTE-cancer study. Thromb Haemost, 2015; 114: $1268-1276$ 